\title{
@ccreative
}

BY-NC-SA 4.0

UMÁTICA. Revista sobre Creación y Análisis de la Imagen

\{ISSN: 2659-5354// D.L.: MA- 1628-2018\}

\section{Berrocal y la estética transhumanista}

\section{Una mirada transhumanista de la obra de Berrocal*}

Berrocal and the transhumanist aesthetic: A transhumanist view of Berrocal's work.

\section{Agustin LiNAREs PedRERo}

Universidad de Málaga

La obra de Miguel Berrocal siempre es referida y recordada como un ejemplo de "arte matemático", un adjetivo que tiene su sentido por ser de los artistas que aúnan en su obra escultórica la ingeniería y el arte. Para algunos, sus obras recuerdan al trabajo de un joyero o un relojero, un artesano que ha superado la línea que fue dibujada en el siglo XVIII y se ha convertido en artista. Hay, sin embargo, en sus métodos y su temática unas constantes que están siendo obviadas, que pasan normalmente desapercibidas, y que nos permiten encuadrar la obra de Berrocal en un horizonte mucho más moderno: el transhumanismo. En este breve artículo examinaremos los planteamientos filosóficos y estéticos claves del arte transhumanista y de la obra de Berrocal en busca de la correlación que nos permita hacer una relectura de su obra y actualizar su lugar en nuestra cultura artística y estética.

Artículo original Original Article

Correspondencia Correspondence

Agustín Linares pedrero@uma.es

Financiación

Fundings

Sin financiación

Received: 15.02 .2020

Accepted: 24.04 .2020

CÓMO CITAR ESTE TRABAJO / HOW TO CITE THIS PAPER

Linares, A. (2020). Berrocal y la estética transhumanista. Una mirada transhumanista de la obra de Berrocal*. Umática. Revista sobre Creación y Análisis de la Imagen, 2: 53-74.

https://doi.org/10.24310/Umatica.2019.v1i2.7880 
Berrocal and the transhumanist aesthetic:

A transhumanist view of Berrocal's work

Agustin LinAREs PEDRERo

Universidad de Málaga

Abstract:

Miguel Berrocal's art is always referred to and remembered as an example of "mathematical art", an adjective that has its meaning because it is one of the artists who combines engineering and art in his sculptural work. For some people, his works are reminiscent of the work of a jeweler or a watchmaker, a craftsman who crossed the line that was drawn in the 18th century and has become an artist. There are, however, some constants in his methods and his subject matter that are being ignored, that normally go unnoticed, and that allow us to frame Berrocal's work in a much more modern horizon: transhumanism. In this brief article we will examine the key philosophical and aesthetic approaches to transhumanist art and Berrocal's work in search of the correlation that will allow us to re-read his work and update its place in our artistic and aesthetic culture.

KEYWORDS: transhumanism, art, robotics, Berrocal, sculpture, aesthetics

Summary - Sumario:

1. Introducción

2. Fuentes y Metodología

3. Automátas, Robots, Ciborgs y Transhumanismo.

3.1. Automátas.

3.2. Robots

3.3 Ciborg y Transhumanismo.

3.4 Estética Transhumanista.

4. Referencias

5. Conclusiones 


\section{Introducción}

Es patente, que la obra del escultor Miguel Ortiz Berrocal es una obra de alta singularidad, entendida y admirada por sus coetáneos. Siendo valorado en su tiempo como superviviente del Arte Nuevo español, la aventura vanguardista y renovadora que vivió el arte español antes de la Guerra Civil, sus fuertes influencias de la arquitectura y su fijación por lo "múltiple" industrialmente producido, lo han llevado a ser habitualmente valorado como un artista "matemático". Una posición extraña para el imaginario popular, que lo deja apartado de la corriente histórica. Sin embargo, desde una mirada moderna, hay en su obra planteamientos que nos recuerdan a los fundamentos que directamente hablan de la transgresión de los límites de la corporeidad del hombre o de la alteración de sus modos de representación, ideas que conectan con la robótica, los androides y el transhumanismo. Nuestro objetivo en este artículo será comprobar si es posible hacer una relectura de los procesos y obras de Berrocal en clave transhumanista. Para ello examinaremos la conexión que la obra de Berrocal -en obras datadas de 1969 en adelante- y su metodología pueden establecer con las principales ideas transhumanistas, remarcando el trazado filosófico y estético que lo posiciona como antecesor y pionero -intencionadamente o no- del arte robótico, futurista y transhumanista.

El transhumanismo es la respuesta a una colección de inquietudes por los límites del ser humano, las relaciones cuerpo-mente y humano-máquina, que en el siglo XX y XXI se diversifican con la aparición de los ordenadores, los robots y la inteligencia artificial. Precisamente por eso, es en la década de 1990 cuando aparece uno de los mayores defensores del transhumanismo como movimiento, Max-More, cuyo trabajo tiene como objetivo mejorar nuestras capacidades intentado anticiparse al futuro (Vita-More, 2012). Si bien es cierto que se ha consolidado en la historia reciente como el ejemplo del transhumanista, en realidad, el movimiento surge mucho antes. Como recoge su hija Juliette, fue Julian Huxley, biólogo evolutivo, quien acuñó el término transhumanismo para referirse a la perspectiva según la cual los seres humanos deben mejorarse con ciencia y tecnología (1986:204). Huxley fue parte de los fundadores y primer director de la UNESCO por la misma razón que desarrolló el concepto transhumanista: le preocupaba el terrible estado de la vida natural y humana que observó en sus viajes por el mundo y creía firmemente que somos nosotros, los seres humanos, quienes tenemos que hacer lo necesario para mejorarlo. Hay discusión sobre hasta que punto Huxley invento el término, y es muy cierto que las idea de Huxley eran un reflejo de las preocupaciones de su época y de la fe en las posibilidades de la ciencia para solucionarlos. En esta línea, si quisiéramos ir más atrás en la búsqueda de antecedentes, Dard y Moatti (2016) se retrotraen hasta P. Teilhard de Chardin en 1915, quién creía que ya estaba emergiendo un nuevo nivel de complejidad e inteligencia inaudito. Teilhard llamó a este nuevo nivel la "noosfera", el mundo de la mente cada vez más interconectado, pronosticando así internet y hablando de una curva de la evolución creciente en interconexión hasta llegar a algo que denominó "punto 
Omega" - singularidad - Es un anuncio anticipado a lo que supondrá un gran avance tecnocientífico de gran influencia y transformación de las vidas humanas.

Pero, sin duda, es a partir de los noventa cuando comienza su auge, como recoge Kurzweil (2012), solo cuando la posibilidad de una singularidad tecnológica es determinable en términos técnicos y científicos los transhumanistas recogen esta singularidad para aplicarla al aumento de la longevidad exponencialmente. Sin embargo, como acertadamente apunta Bostrom (2011), eso no quiere decir que los filósofos transhumanistas estén de acuerdo con estas condiciones. Existe una corriente crítica y otra optimista, pero ambas intentan exponer los problemas derivados de la actividad humana. El transhumanismo es la visión anticipada de un futuro donde algunas de las tecnologías pueden prolongar o mejorar nuestros cuerpos biológicos, sustituyendo parte o la totalidad de nuestra envoltura física, exceptuando el cerebro. Es un punto de máxima importancia: la sustitución o reconstrucción de nuestro cerebro por otro no biológico - la descarga de la conciencia-, sería la desaparición total del cuerpo humano desembocando así en la idea del posthumanismo, otra tormenta de conceptos en la que no procede profundizar.

Aunque parezca una corriente excéntrica, propone un amplio abanico de debate sobre todas las cuestiones humanas — sociales, económicas, éticas, legislativas, culturales, filosóficas, etc.- implicadas en la posibilidad de que la convergencia NBIC llegue a suceder. El asunto del transhumanismo no es tanto si llegaremos o no, sino crear un debate sobre el futuro que nos haga reflexionar en el presente de las repercusiones de lo que hacemos ahora, poniendo en cuestión muchos de los debates humanos que creemos bien sabidos. De este modo, es fácil deducir que esta perspectiva genera también nuevas visiones y nuevas interpretaciones en diferentes facetas de la creación como la literatura, el cine, o el arte.

El éxito del transhumanismo podría resumirse en la eterna y ahora renovada promesa de la inmortalidad, actualizada por los avances científicos y tecnológicos. En resumen, algunas de las ideas que creemos esenciales del pensamiento transhumanista en base a toda la bibliografía consultada son: Un cambio significativo en la morfología del ser humano, una mejora de las capacidades humanas por medio de la ciencia, el concepto de persona y la apreciación de sus dimensiones, la supervivencia en entornos peligrosos y la hibridación con la máquina. Cuando hablemos de estética transhumanista, nos referiremos a las características visuales que condicionan la referencia antropomorfa y que puede describirse $-y$ complementarse - por alguna o varias de las siguientes adjetivaciones: hibridado, hierático, protésico, máquina, mecánico, robótico, modificado, ampliado, superado, evolucionado. Estas están extraídas de los siguientes autores cuyas obras se referencian en la bibliografía consultada: Según Parsons y Kearsley (1982) quienes introducen la división del trabajo y las diferencias funcionalidades de la importancia estética donde se prima la practicidad y la funcionalidad como características de lo mecánico o lo robótico, en adjetivo como hierático; Fernando Torrijos (2004) habla sobre el culto al cuerpo y aspecto pulido y perfeccionista, tocando adjetivos como lo ampliado, superado y evolucionado; Donna Haraway (1991) anuncia una estética realista y tecnológica, así como la disolución del sexo/género, dando prioridad a 
adjetivos como hibridado y modificado; y por último Natasha Vita-More (2010)니 la aportación que nos interesa de esta autora es sobre una estética de mejora relacionado con lo protésico, lo modificado.

\section{Fuentes y Metodología}

Las herramientas para el estudio son el análisis cultural de textos y la obras de Berrocal, las cuales son muy variadas: fotografías de obras de Berrocal - procedentes del archivo documental de la Fundación Berrocal y de internet - y bibliografía especializada Respecto a la metodología realizaremos una comparativa de características estéticas, donde las imágenes evidencian similitudes o diferencias con una selección de visiones actuales antropomorfas, combinada con una metodología deductiva indirecta.

Partiendo de la premisa general de que el arte se alimenta de su tiempo y de la tecnología, y comparando esto con la premisa particular de que el artista contemporáneo Berrocal trabajaba con una curiosa y característica forma de componer sus piezas, podemos aventurar que su obra contiene muchos aspectos coincidentes con la denominada estética transhumanista, la cual comienza a cristalizar ahora como una heredera del trabajo artístico, el cual hunde sus raíces en la tradición de la construcción de autómatas.

Esta filosofía, aunque de actualidad, no es más que un pensamiento basado en la antigua y extendida idea aludida con el mito de Prometeo, seres mejorados y más cercanos a su -Dios- padre creador. Nos gustaría hacer notar que transhumanismo y posthumanismo no son una invención cultural reciente, sino el germen de una semilla que ha ido fraguándose lentamente al abrigo del auge de los desarrollos tecnológicos, y del cual muchas ideas debían/podían ser conocidas o intuidas por el intelecto de Berrocal.

\section{Autómatas, Robots, Ciborgs y Transhumanismo}

Si bien la tecnología, la ciencia y el arte son disciplinas separadas también son marcos explicativos comunicantes que se configuraron en las doctrinas filosóficas de la Grecia del s. IV a.C. Como nos indica M. Medina (2003), Platón introdujo una división básica, a un lado prácticas y procedimientos técnicos; y al otro ciencia (episteme) y cultura filosófica. Pero si la ciencia mantiene un vínculo con la tecnología, la relación del arte y la tecnología (herramientas, soportes y medios) no ha sido menos íntima, incluso como motor en la producción de nuevas tecnologías o directamente generándolas -como la perspectiva en el Renacimiento-. Ahora bien, estos vínculos parten desde que la humanidad genera objetos o pinturas primitivas -usando las más elaboradas herramientas y medios-, hasta la actualidad con la sofisticación de la electrónica y la computación de información. Cabe destacar, por tanto, que la historia del arte es fe-

\footnotetext{
${ }^{1}$ Blade Runner se estrena en 1982, y al año siguiente Natasha Vita-More publica el primer manifiesto del transhumanismo. Es presidenta de la organización Humanity Plus.
} 
cunda en hitos y ejemplos en los cuales el avance tecnológico fue recogido por el arte para empujar sus representaciones e ideas a un nicho más alto. ${ }^{2}$

Comentada la relevancia de la tecnología para el mundo del arte y viceversa, en la contemporaneidad este vínculo es más estrecho si cabe, dado el abrazo de gran parte del mundo del arte al avance electrónico e informático, hecho fácilmente deducible dada la tradición que nos precede. No debe extrañarnos entonces, que en el desarrollo del arte, antes de tocar los ordenadores, encontremos en la historia y el arte ejemplos de figuras animadas eléctrica o mecánicamente.

Desarrollando la idea de Prometeo, encontramos la obra de "Frankenstein" como célebre moderno Prometeo (Frankenstein or The Modern Prometheus) de Mary Shelley (1818) donde como ya sabemos se narran las desagradables aventuras del científico Victor Frankenstein y su criatura, en medio de un imaginario romántico. La posteridad y las ficciones postreras llamarán a Frankenstein, el monstruo, insuflando así parte del miedo que se ha representado en arte, literatura y cine a lo largo del tiempo. Miedo a la evolución, a la conquista de un poder divino, que desde entonces hasta nuestros días emerge cada vez que se trata el tema de la mejora humana incluye también este miedo.

\section{1. Autómatas}

El mito de Frankenstein lleva mucho tiempo forjándose, desde los primeros escritos como son "El libro de Thot" en Egipto, "El Antiguo testamento", "El Golem" judío, la mitología griega con Prometeo, "La llíada" o "Pygmalión", donde los dioses castigan a los humanos por desafiar los poderes naturales. Pero estas ficciones tomarán forma física con los autómatas musicales diseñados por el ingeniero Jacques Vaucanson ${ }^{3}$ (1709-1782), como son sus célebres representaciones llamadas El Pato (fig. 1). También tenemos el ejemplo del flautista de Innocenzo Manzetti (fig. 2), dando vida -simuládamente- a un ser de materias inertes. Esta fascinación de Vaucanson y Manzetti son ejemplos de una pasión obviamente compartida con Goethe, puesto que ambos recrean seres de artificio utilizando estrategias distintas. Goethe incorpora la fábula del homúnculo a la leyenda de Fausto publicada en 1808. Un ser que existe, pero sin forma, que contiene todas las cualidades espirituales, pero faltándole lo tangible, lo real y matérico. En cambio, Vaucanson realizó justo el ejercicio inverso, un cuerpo animado desprovisto de alma, el resultado debió ser tan fascinante para Diderot y

\footnotetext{
2 Leona herida - por la cerámica vidriada y sus esmaltes azules-, El sarcófago y la máscara de Tutankamón (1300 a.C.),-microfusión de metales preciosos-, Dios del cabo Artemisios, (460 a.C.) -fundición de bronce con moldes a la cera perdida- El Laocoonte (50 d.C.), - desarrollo de herramientas sofisticadas como taladros y transportador de puntos-, La Anunciación (1430) -por la perspectiva-, Retrato ecuestre a Felipe IV (1640) -ingeniería de Galileo Galilei-, así muchos más con tecologías como la impresión para El caballero, la muerte y el diablo(1513) de Durero, los pigmentos químicos para el movimiento impresionista, la fotografía, el cine, el video, etc.

3 Jacques Vaucanson también era un inventor efectivo de máquinas industriales (tornos metálicos, máquinas de tejer). Imaginar criaturas humanas mecánicas es un evento parejo la creación de las primeras máquinas industriales, pero por esa actividad de recreación de autómatas hoy día se le podría llamar artista.
} 

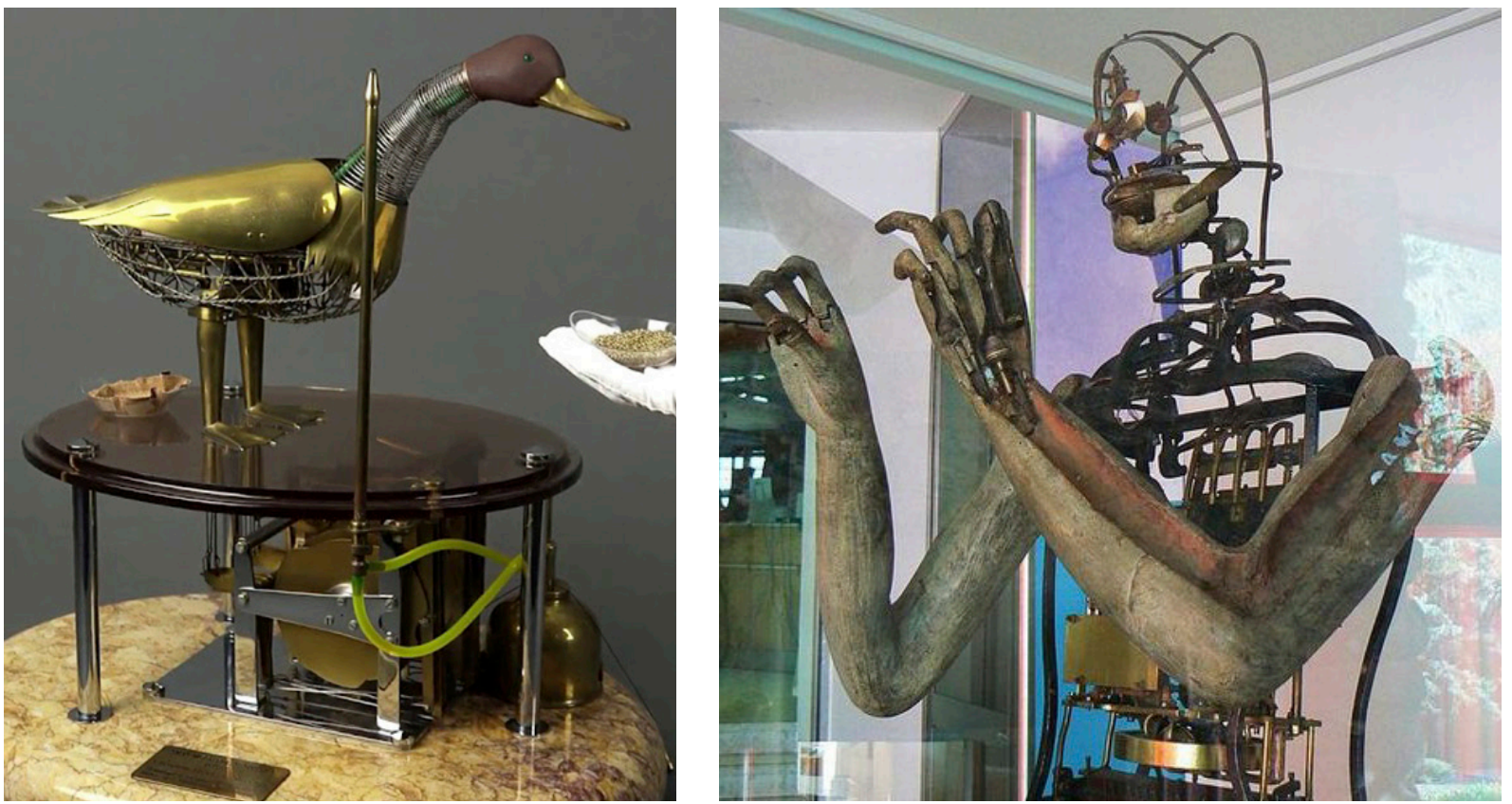

D'Alembert que en su L'encyclopédie en la parte dedicada al androide (1751, Vol.1, p. 448-451) dieron una amplia descripción de la existencia física de tales entidades, colocando la maravilla técnica del autómata de Jacques Vaucanson en el escenario de la iluminación como objeto de ciencia y desterrando el término androide de la leyenda. Recogiendo esto, en 1933, Berrocal recreó una pieza llamada Paloma Jet (opus.143, fig. 3), donde encontramos aquí tres rasgos interesantes que conectan con lo dicho anteriormente sobre la ciencia, el arte, y la simulación animada de seres inertes.

Como escultor es evidente su pasión por las artes, pero también por las humanidades, exponemos el ejemplo Paloma Jet (fig.3), donde realiza un alarde de destreza añadiendo a su estilo de construcción -en puzzle tridimensional- la capacidad de articularse, abriendo y cerrando las alas y la cola, descubriendo unos atributos aeronáuticos, constituyendo la primera de muchas de sus obras articuladas como parte de sus propiedades efectivas. Por tanto, la fabricación de los primeros autómatas mecánicos no debió pasarle desapercibida -en su biblioteca se encuentran ejemplares como el de Juanelo Turriano ${ }^{4}-$ y dentro de su gran producción también queda patente. Ante lo dicho, se hace evidente la conexión de Berrocal con la ciencia y su argucia matemática constructiva, tanto fue así que esta pieza fue destacada en la revista Scientific American según aduce Gardner (1978, p.14-26).

Estos dos rasgos son dos de las constantes en la obra de Berrocal, su capacidad de reunir estética e ingeniería, -ciencia y arte- a la que se suma un estilo propio en la representación. Como continuación de nuestro recorrido hemos de decir que parece lógico que el siguiente paso sea mostrar ejemplos de autómatas y el arte en relación a la robótica.

\footnotetext{
${ }^{4}$ Ingeniero del Renacimiento al servicio de Carlos V y de Felipe II conocido por sus obras hidráulicas y la realización de autómatas.
}

Umática. 2019; 2: 53-74

Fig. ol.

Pato, de Jacques de Vaucanson, 1738 [Adaptado por John Rieffel, 2007]

Fig. 02.

Torso superior del Flautista, de Innocenzo Manzetti, 1849 [Adaptado por Elena Tartaglione, 2011] 


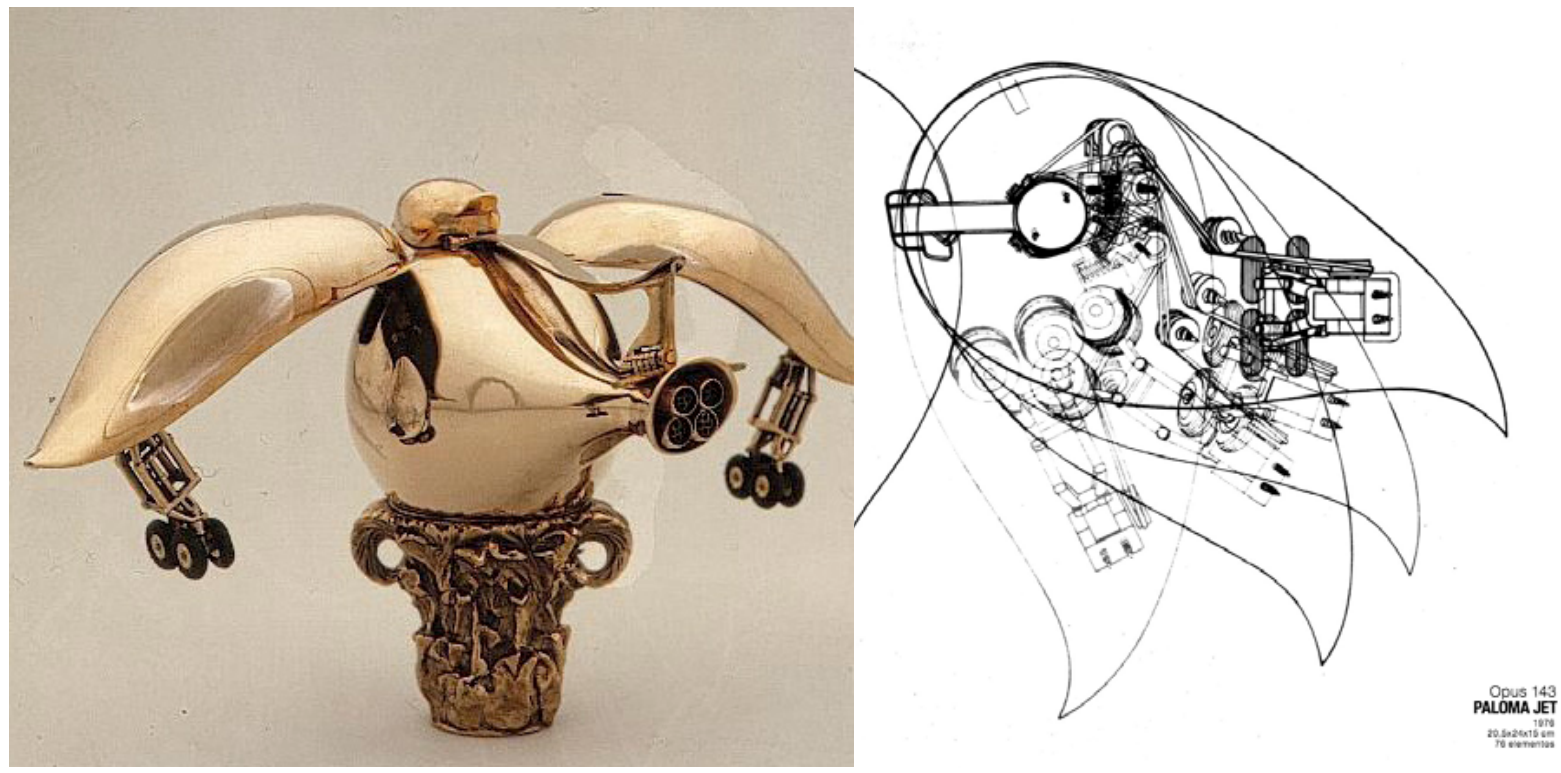

Fig. 3. Paloma Jet. Opus 143. Miguel

Berrocal, 1979. Imagen facilitada por la Fundación

Escultor

Berrocal, 2008

Fig. 3.1.

Detalle de Paloma Jet. Opus 143. Miguel

Berrocal, 1979, Imagen facilitada por la Fundación

Escultor

Berrocal, 2008.

\subsection{Robots}

Las construcciones de autómatas parecen ser los precursores del robot, entre otros muchos ejemplos que irán surgiendo en la historia, configurándose como un ser reanimado y reconstruido de partes diferentes y unos objetos que emulan propiedades de los seres vivos, -lo que cristalizó bajo el término de robot ${ }^{5}$ - y este ejercicio de reconstrucción requiere inevitablemente una estética asociada.

En el caso de los entornos de servicio, los robots comparten contextos físicos con las personas a través de actividades e interacciones (como los recepcionistas), relaciones sociales (robots mascota) y artefactos de limpieza y gestión de almacenaje. Por tanto, su aspecto determina un valor muy importante en la comunicación con el espectador, incluso la forma en la que los referimos, interpretamos o enjuiciamos. Puesto que, a través de todas estas facetas, un robot establece automáticamente relaciones implícitas con el espectador, y esa interrelación sigue estando presente de manera reflexiva en la actuación contemporánea; tal como Stephens y Heffernan (2016) nos lo argumentan en su ensayo "We Have Always Been Robots: The History of Robots and Art".

En relación con lo dicho, en el mundo del arte ha habido varios ejemplos de contacto con la estética robótica, conformando parte del arte robótico. Una parte son los robots como generadores de piezas artísticas, y otra parte son los robots que son artísticos por su conjunto de acciones y/o estéticas - que es la parte que en este caso nos interesa- entre muchos más casos exponemos como ejemplos: Nicholas Schöffer con el nombre "CYSP-1" -1953 (fig. 4);

${ }^{5}$ El término 'robot' lo escribieron los hermanos Capek, variando la palabra checa 'robotnik' que significa 'trabajador' o 'siervo'. Los hermanos Capek escribieron la obra teatral R. U. R. (Robots Universales Rossum, 1920, estrenada en 1921), obviamente influenciados por la obra Pigmalión.

Umática. 2019; 2: 53-74 

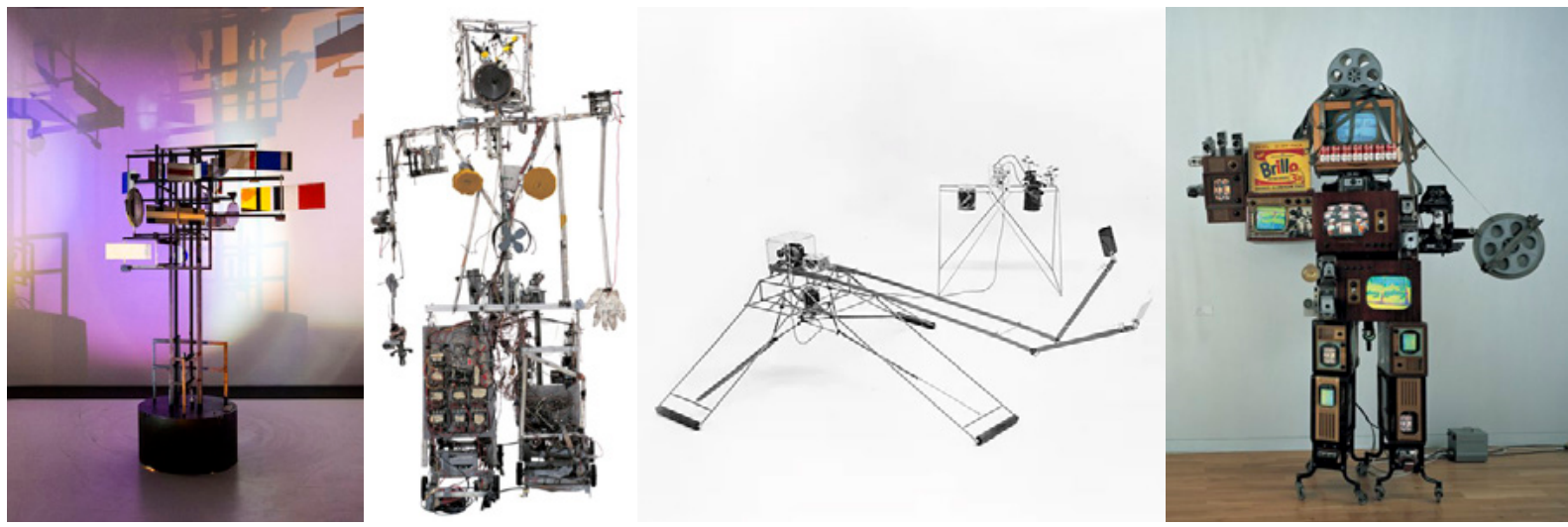

Nam June Paik y Shuva Abe con K-456 -1964 (fig. 5); o Tom Shannon con la obra llamada Squat-1966 (fig. 6); sus propósitos implicaban acciones de simulación a los seres vivos, pero el mismo Paik realiza más tarde robots con televisores como Andy Warhol Robot (fig. 7).

Con esto queremos hacer notar, cómo a mediados del s. XX ya existe una respuesta desde el mundo del arte sobre la idea de robot como elemento de trabajo. Ahora bien, aunque la inspiración de Berrocal en su serie de esculturas Almogávares fuese la del grito de guerra: ¡Desperta ferro! -cómo destila en su entrevista el periodista José Luis Picón, en un artículo en la agencia EFE (Picón, 2019), a Cristina Braganza (viuda del escultor) en la inauguración de la exposición en el Museo de la Aduana en Málaga el 11 de dic. Del 2019- somos de la opinión que el escultor Berrocal tenía una intensa producción y anduvo más preocupado por el desarrollo y evolución expresiva de las piezas finalizadas, que del título en sí, y estas eran nominadas más bien por las inquietudes intelectuales momentáneas. Por ejemplo, esta serie de esculturas consisten en el trabajo de deconstrucción y reconstrucción de unos yunques que adquirió, a partir de los cuales comenzó su trabajo estructuralmente, como afirma el mismo texto de la entrevista, antes citado. En mi opinión, el artista trabajaba para dar una solución compositiva y estética a un excedente de materias primas como reto a resolverlos yunques industriales adquiridos- obteniendo como resulta unos torsos antropomorfos de gran belleza y argucia compositiva, fruto de una mente muy moderna para su época, más propios de ciencia ficción que de los soldados del s. XII -los cuales no portaban armadura, por cierto-.

Para reforzar esta especulación, quiero mostrar una imagen de los Almogávares (fig. 8) y compararla con otra titulada Fruela I en homenaje al Rey de Asturias del 757 (fig. 9). Esto podría hacernos entender que el título, al menos en parte de sus obras, es una excusa para alimentar su expresividad, y que efectivamente el artista trata de hacer emerger del interior de la forma humana, una cuarta dimensión del ser, por medio del metal como materia prima elemental. Tal y cómo el mismo escultor parece exponer en su propio catálogo de su obra escrito por Hamburski (1985).

Simplificando su descripción, las esculturas resultantes producidas representan unos torsos de metal -puesto que la obra de Berrocal es antropocéntrica, prácticamente en su

Fig. 4 . CYSP-1 de NicolasSchoffer, 1956. [Adaptado de IDIS, por Carlos Trilnick, 2019]

Fig. 5 .

K-456 de Nam June Paik y Shuva Abe (ingeniero), 1964 [Adaptado de Artsy, por Nam June Paik, 1964

Fig. 6.

Squat de Tom Shannon, 1966. [Imagen facilitada por la web personal de Tom Shannon].

Fig. 7.

Andy Warhol

Robot" de Nam June Paik, 1994 [Imagen facilitada por Helge Mundt] 

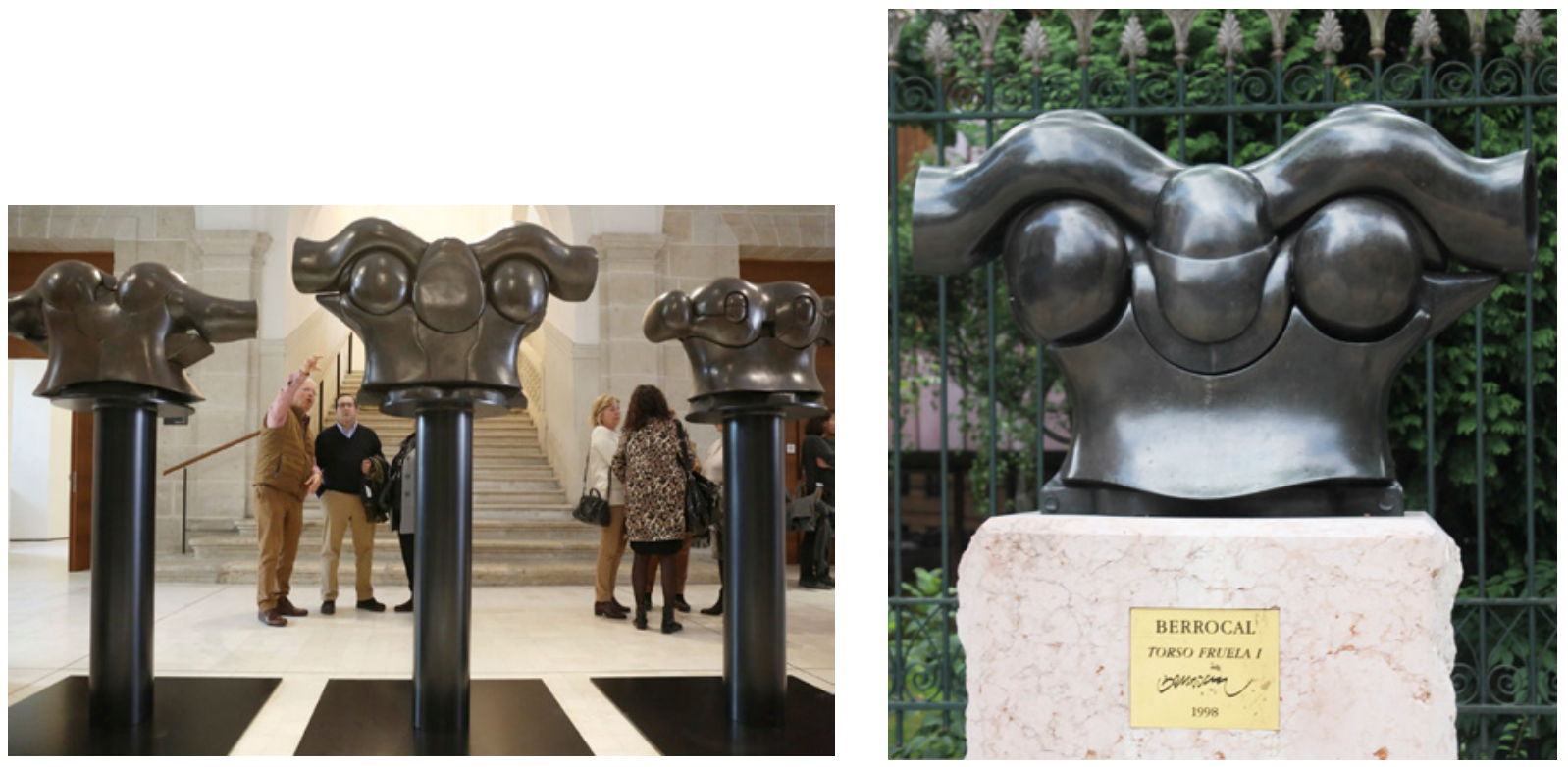

Fig.8 totalidad-, construidos a partir de piezas ensambladas, que intencionalmente o no, bien poAlmogávares. Miguel Berrocal, drían estar más conectadas con la definición de robot anteriormente escrita.

A mi entender, estas figuras son ciertamente muy semejantes, y aunque con títulos com[Imagen facilitada pletamente diferentes, y forman parte de una línea de trabajo continua, característica en el por EFE, 2019].

Fig. 9

Torso de Fruela. escultor. También cabe decir, que se pueden apreciar muchas semejanzas estéticas con lo que aparentan ser declinaciones de un ideario de máquina o robot -estéticamente hablando-, como nos induce Robert Morgan (1999) con términos como desarmado, reconstruido, Miguel Berrocal, 1998. ensamblado. También el autor habla en la entrevista de máquina de realidad, (Morgan, 1999: 127).

[Adaptado de Wikimedia, por Bartomeu Caldentey Vives, 2015].

Para ello vamos a exponer algunos ejemplos comparando estas piezas de Berrocal con ejemplos de robots sacados de la imaginación artística (fig. 10,11 y 12) y con ejemplos de robots reales construidos por la industria (fig. 13, 14 y 15). Pueden apreciarse los volúmenes geométricos exacerbados, de hecho, María de Metrópolis es la figura de la mujer y la máquina fundida en una estética robusta y enérgica que representa la fortaleza incansable, donde el alma de María transmigra al robot. Afrodita-A es un robot gigante, de colores cálidos, habitado por un ser humano, representando la mujer ágil y fuerte, unida a una marcada feminidad. O el caso de Robocop, que encarna al hombre reconstruido casi íntegramente debido a un incidente laboral, balanceándose entre el transhumanismo y el posthumanismo.

Si bien parte del arte trabaja con las técnicas e incertidumbres que tiene en su entorno social y temporal -y la robótica lo es también-, era previsible que el arte tocase estos temas (fig. 7). En la actualidad, nuestro mundo cada vez más conectado y robotizado ha configurado el concepto de singularidad tecnológica, el cual rescata términos como ciborg y transhumanismo que están siendo tratados por el arte (fig. 22). 

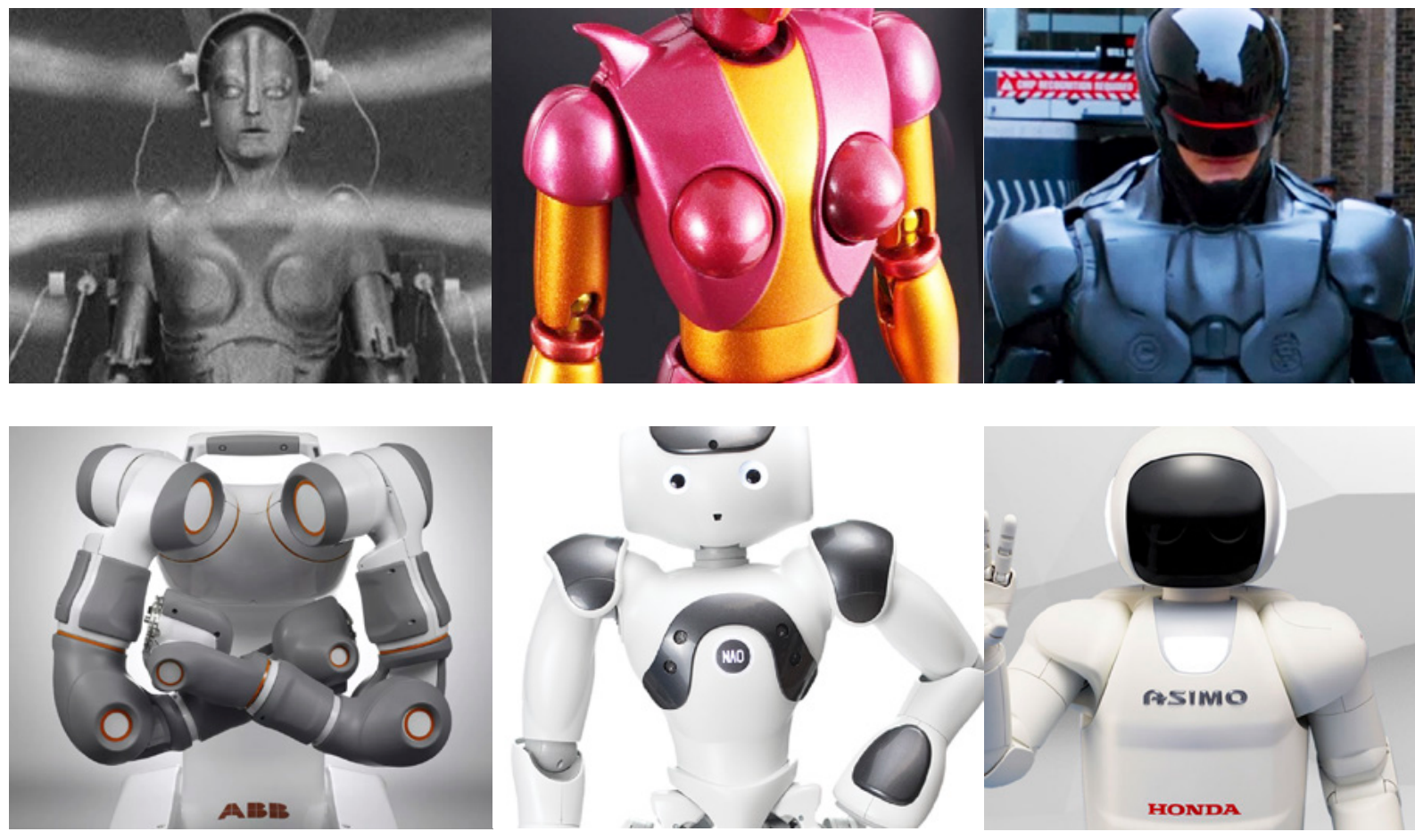

\subsection{Ciborg y Transhumanismo.}

El término ciborg -cibernetic organism- fue acuñado en 1960 por Manfred E. Clynes, quien junto con Nathan S. Kline (1960) trataban de definir a un hombre mejorado que podría sobrevivir en una atmósfera extraterrestre: "Los viajes espaciales desafían a la humanidad no sólo tecnológicamente sino también espiritualmente, ya que invitan al hombre a tomar parte activa en su propia evolución biológica" (Clynes y Kline, 1960: p.26). Un humano hibridado con la máquina, mejorando los aspectos de su fisionomía, así como sus capacidades.

Katherine Hayles (1999: pp.2-3) alega que "el cuerpo es una prótesis primigenia que todos aprendemos a usar". También afirma que "el hombre puede ser reconfigurado para articularse perfectamente con las máquinas inteligentes".

A diferencia del ciborg, lo transhumano se basa en la filosofía y sus aspectos sociopolíticos y económicos, y encuentra en el ciborg una plataforma que posibilita su materialización física.

Según Clynes (1960), el ciborg es consistente con el concepto transhumano de evolución autodirigida, y el ciborg terminaría superando la condición biológica de la naturaleza humana. Pero para el autor, existen varios factores que deben estar incluidos como la ética y los derechos humanos.
Fig. 10

María, Robot de

Metrópolis, 1927.

Fotograma de la

película Metrópolis,

de Fritz Lang.

Fig. 11

Detalle de la figura de Afrodita-A de Mazinger Z, 1956.

Figura del robot

Afrodita A de

Mazinger Z, diseño de Go Nagai

Fig. 12

Robocop, personaje principal de

Robocop, 2014.

Fotograma de la película Robocop, de José Padilha
Fig. 13

Robot FRIDA

de ABB, 2011.

Adaptado del

artículo de

presentación

oficial de

Spectrum IEEE

Fig. 14

Robot NAO de

SoftBank Robotics V6, 2006.

Imagen facilitada por SoftBank

Robotics, 2006

Fig. 15

Robot Asimo de

Honda, 2000.

Imagen facilitada

de Honda, 2020 
Podemos considerar entonces, que el transhumano será una transición con etapas de desarrollo, dependiente de las ciencias y tecnologías disponibles, teniendo en cuenta también los problemas sociales y políticos que podrían apoyar o frenar su progreso.

Al parecer, el término transhumanismo apareció a principios de la década de 1950, de la mano Julian Huxley. Según el ensayo de Peter Harrison y uno de sus alumnos, Joseph Wolniak, mostraron que Huxley usó la palabra ya en 1951, y ponen de manifiesto que Huxley pudo haber tomado el término de otro autor. Todo ello queda patente en el ensayo de Harrison y Wolniak (2015) que apareció en la revista Notes and Queries. Pero siguiendo la estela de J. Jairo Cardozo y T. Meneses Cabrera (2014) debemos citar su introducción:

De acuerdo con los especialistas, el concepto de transhumanismo se desarrolla como bisagra a partir de dos aspectos: 1) como concepto filosófico y 2) como un movimiento intelectual de alcance internacional, cuyas construcciones están basadas en el uso de la ciencia y la técnica (tecnología), para el desarrollo mental y biológico de los seres humanos. [...]

[...] El transhumanismo aboga por el surgimiento de un humano mejorado tecnológicamente e inmune a muchos efectos colaterales, que incluso él mismo ha generado. En este sentido, el símbolo por el que han optado los transhumanistas es $\mathrm{H}+$ para representar dicho estado de superación. Por esto, el transhumanismo considera que la actual esfera orgánica en la que nos encontramos es solo una fase de lo que podría en un futuro mejorarse biotécnicamente, a fin de generar posibilidades insospechadas para nuestra especie bajo cuatro coordenadas: Nanotecnología, Biotecnología, tecnologías de la Información y la comunicación, y tecnologías Cognitivas. (p.66)

Estas conforman la denominada "convergencia NBICS"॰ (Nanotecnología, Biotecnología, tecnologías de la Información y la comunicación, y tecnologías Cognitivas) y es que desde la visión transhumanista la naturaleza humana se considera algo en proceso, no finalizado, en continua auto-reconstrucción, determinado no solo por el deseo, sino también por lo deseable o lo imaginado.

Siguiendo los orígenes que Dard y Moatti (2016) plantean sobre el transhumanismo, a grandes rasgos, todo gira en torno a la idea de la posibilidad de transformar al hombre, de mejorarlo, llevar a la humanidad a otro peldaño evolutivo. La premisa de partida es que el desarrollo tecnológico puede alterar profundamente a los seres humanos, y declaran que el transhumanismo es uno de los movimientos filosóficos y culturales más polémicos en los úl-

\footnotetext{
${ }^{6}$ A finales del 2001, el gobierno de los EEUU realizó un foro de discusión para el desarrollo de proyectos de alta tecnología, del cual surgió un documento donde aparecía la posible convergencia de las NBICS firmado por: R. Asher, D. M. Etter, T. Fainberg, M. Goldblatt, C. Lau, J. Murday, W. Tolles, G. Yonas. citado por Jim Spohrer, NIBCS (Nano-Bio-Info-Cogno-Socio) Convergence to Improve Human Performance: Opportunities and Challenges, Converging Technologies for Improving Human Performance, p. 90.
} 
timos tiempos, un debate aún abierto que augura un uso democrático de la tecnología para el progreso de la condición humana en los aspectos más esenciales -conceptual y físico-, trascendiendo los actuales límites de lo humano.

Este término está más de moda que nunca debido a los numerosos discursos, artículos de prensa, así como los ensayos académicos y producciones de ficción, y está empezando a ser usado también en arte.

\subsection{Estética Transhumanista.}

El transhumanismo, no es algo espontáneo, conserva elementos de corrientes humanistas pasadas, y también mantiene el mismo núcleo común: la fascinación histórica de los humanos por el propio ser humano y su mejora. Si lo distintivo de la forma del propio cuerpo-además de las emociones, sensaciones, asimetrías físicas y mentales- ha sido siempre una importante fuente de representación para los artistas de cualquier época, incluso en los albores del sapiens. Y además le sumamos que los defensores` -como P. Singer, J. Harris, A. Sandberg y N. Bostrom, además de los precursores del término citado- del discurso transhumano sugieren que los innovadores avances y las tecnologías emergentes han comenzado a modificar el modelo tradicional de lo humano. Entonces es fácil pensar en la nueva situación venidera como transcendental, y sin duda un potencial tema discursivo para el arte.

El arte que podríamos denominar transhumanista, no debería constreñirse a un arte realizado después de la concepción del término -en 1950-. Sino que por contener un anhelo tan antiguo como el hombre, cabría decir que estaría vinculado a cualquier forma de arte que manipule, cercene o hibride la forma humana estética o conceptualmente, con aspiraciones de mejora o cambio. De esto se desprende que la evolución del robot, en alguna de sus estirpes, sea el ciborg, la unión del hombre y la máquina con la intención de ensamblar lo mejor de ambas singularidades, permitiendo al humano mejorar su recipiente de carne y actualizar su significante.

Así mismo, la convivencia de lo extraordinario y lo mundano, en nuestra especie, nos ha empujado e inspirado a una constante búsqueda de conocimiento y representación artística, permitiendo una representación fisiológica de nosotros y lo sagrado. Encontramos los primeros ejemplos en las venus paleolíticas -como Willendorf-, o en las pinturas rupestres de Tassili-. Esto ha sido parte de la herencia que a lo largo de la historia nos ha llevado por las negaciones de lo corporal, la exaltación de lo espiritual, la mecanización de lo viviente o el antropocentrismo egocéntrico, como nos induce Julio Amador (2017)

Existen más ejemplos en el arte, pero solo comentaremos unos pocos atendiendo a la representación antropomorfa y sagrada, desde los dioses egipcios -hombre con cabeza de animal-, hasta las obras de Stelarc u Orland, pasando por el surrealismo, el cubismo, los retratos de Francis Bacon, Nam Jun Paik, Louis Borgois, Patricia Piccinini, Marcelí-Antúnez, Stijn De Pourcq, etc. - cuestionando la representación de lo humano-.

7 Promotores de la eugenesia liberal y autores de Human Enhancement, Oxford University Press, 2009

Umática. 2019; 2: 53-74 

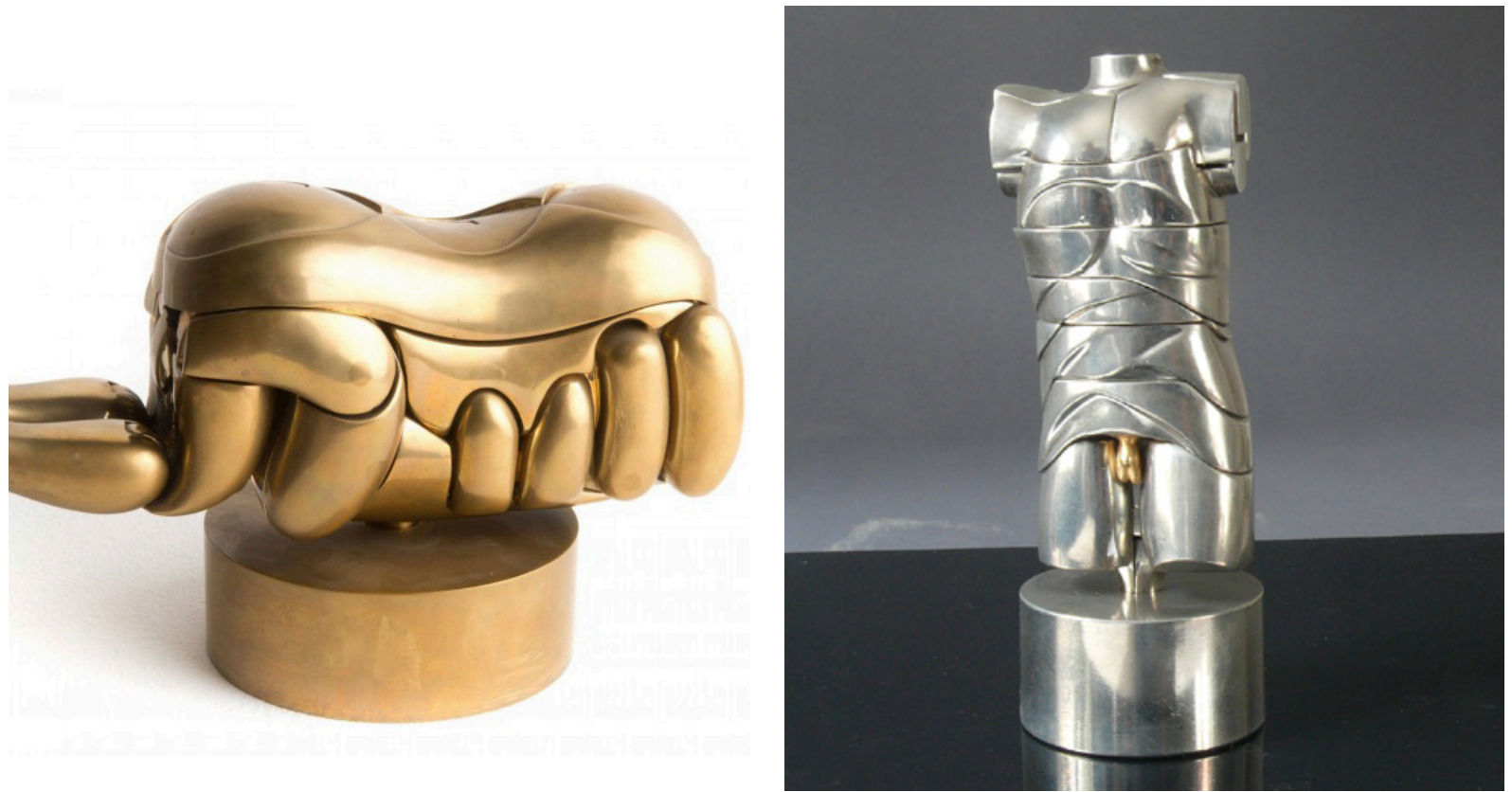

Fig. 16.

Romeo y Julieta, opus 101, Miguel Berrocal, 1969. [lmagen proporcionada por la

Fundación Escultor Berrocal, 2008[.

Fig. 17.

Mini David, opus 107, Miguel Berrocal, 1969. [Imagen proporcionada por la Fundación Escultor Berrocal, 2008].
Se evidencia, por tanto, lo difícil que es dar con una respuesta artística perfecta a la representación antropocéntrica, pero quizás si podemos hallar muchas de ellas como satisfactorias para un momento y lugar determinado, según conocemos de los infinitos ejemplos descritos en la historia del arte. Si afirmamos que un ser humano no puede percibirse a sí mismo desde la objetividad suficiente que brinda la alteridad, encontramos que, por un lado, la percepción del otro sacrifica el conocimiento privilegiado de la mente propia, oscureciendo la complejidad humana. Y por otro, la mirada a uno mismo queda emborronada por la agitada vivencia del presente. Y cuando miramos más allá, respecto a la vida en la sociedad humana, al presente que construimos o al futuro al que nos encaminamos, llevamos siempre este sesgo con nosotros, en la línea que recoge Moya en su obra sobre la filosofía de la mente (2006) en su acercamiento preteórico, evidencia la diferencia de percepción entre nosotros y el resto del mundo.

Después de lo dicho, y dado el afán innovador de los artistas, el arte que pretenda ser efectivamente transhumanista debe arrojarse a lo desconocido y empujar los límites de su propio presente, caminar entre las sombras de la duda para iluminar lo inexplorado e inspirar a la sociedad de su tiempo para que avance en el conocimiento de lo que supone transhumanizarse, convirtiendo en factible o en repudiable lo que hasta ahora era -algo no pensado-mejorar al humano, exorcizando lo positivo y lo negativo.

A grandes rasgos, podríamos hacer la presunción de que la estética transhumanista debería contener una inclinación antropocentrista actualizada, a tenor de las ideas que exhala la filosofía transhumanista en torno a lo humano y la mejora de sus capacidades como idea central. Pero también rupturista puesto que sus ideas chocan con la tradición de la representación de nuestro cuerpo, como induce Natasha Vita-More (2010), y es precisamente 


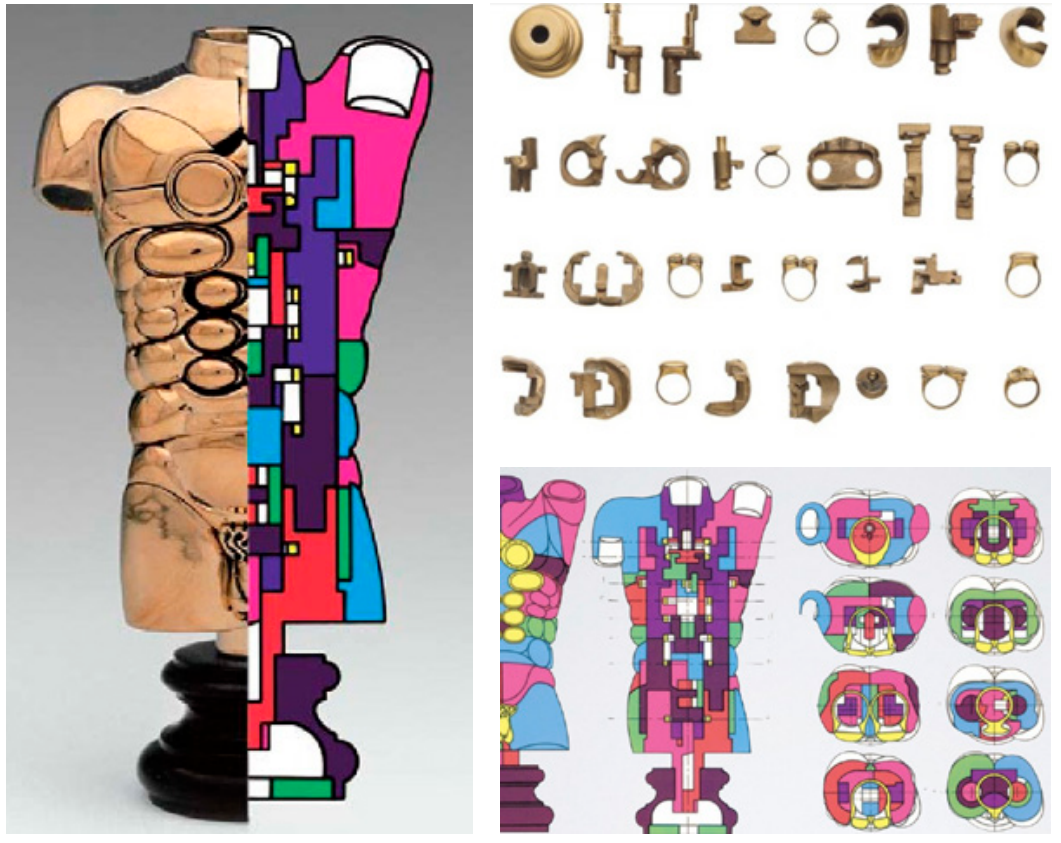

por eso que, como todas las estéticas heredadas ven medidas sus intentos de innovar como transgresiones contra la tradición. Es totalmente comprensible, puesto que el ser humano es reticente al cambio, está en el funcionamiento de nuestro cerebro. Como señalan Charles y Carter (2013) cuando empezamos a salir de las cavernas, la capacidad de recordar lo que funciona -o no- y además resistirnos a probar alocadamente cualquier otra cosa, nos hizo mejores supervivientes. Pero nuestros avances tecnológicos son capaces de alterar nuestro entorno y la manera de relacionarnos con él por encima de nuestra capacidad de asimilación mental y evolución biológica. Siendo así, la ansiedad creciente, el estrés crónico, los sesgos cognitivos de los que abusa la publicidad y el sistema consumista, son solo algunas de las consecuencias de este "hardware" desfasado. Y por tanto otro rasgo estético es la figura humana descompuesta o construida de partes -heredado desde Frankenstein hasta el robot-, la reinvención de la anatomía corporal -la invención de órganos, músculos o fusión con otros seres-, la deformación, la mutilación, la articulación mecánica y/o electrónica, la incorporación de nuevas tecnologías. Son un resumen de lo que podría concentrar la estética transhumanista.

Por tanto, y a tenor a las siguientes piezas de Berrocal: fig. 16, 17, 18, 19, 20 y 21, que no son excepciones, sino variaciones o declinaciones de un trabajo continuo del escultor -estándares de su estilo-, nos atrevemos a afirmar que efectivamente las obras de Berrocal recogen gran mayoría de las características estéticas anteriormente descritas y por ende, al aplicar una visión transhumanista puede revelarse como acertada esta concepción de semejanza, puesto que muchos de los adjetivos que definen a ambas convergen.
Fig. 18.

Alexandre,

opus 113,

Miguel Berrocal,

1969.

[lmagen

proporcionada por la

Fundación Escultor

Berrocal, 2008

Fig. 19.

Piezas y montaje de Alexandre, opus 113,

Miguel Berrocal,

1969.

[lmagen

proporcionada por la Fundación Escultor

Berrocal, 2008

Fig. 20.

Richelieu,

homenaje a Paolo

Marzotto.

Miguel Berrocal,

1973.

[Imagen proporcionada por la

Fundación Escultor

Berrocal, 2008 

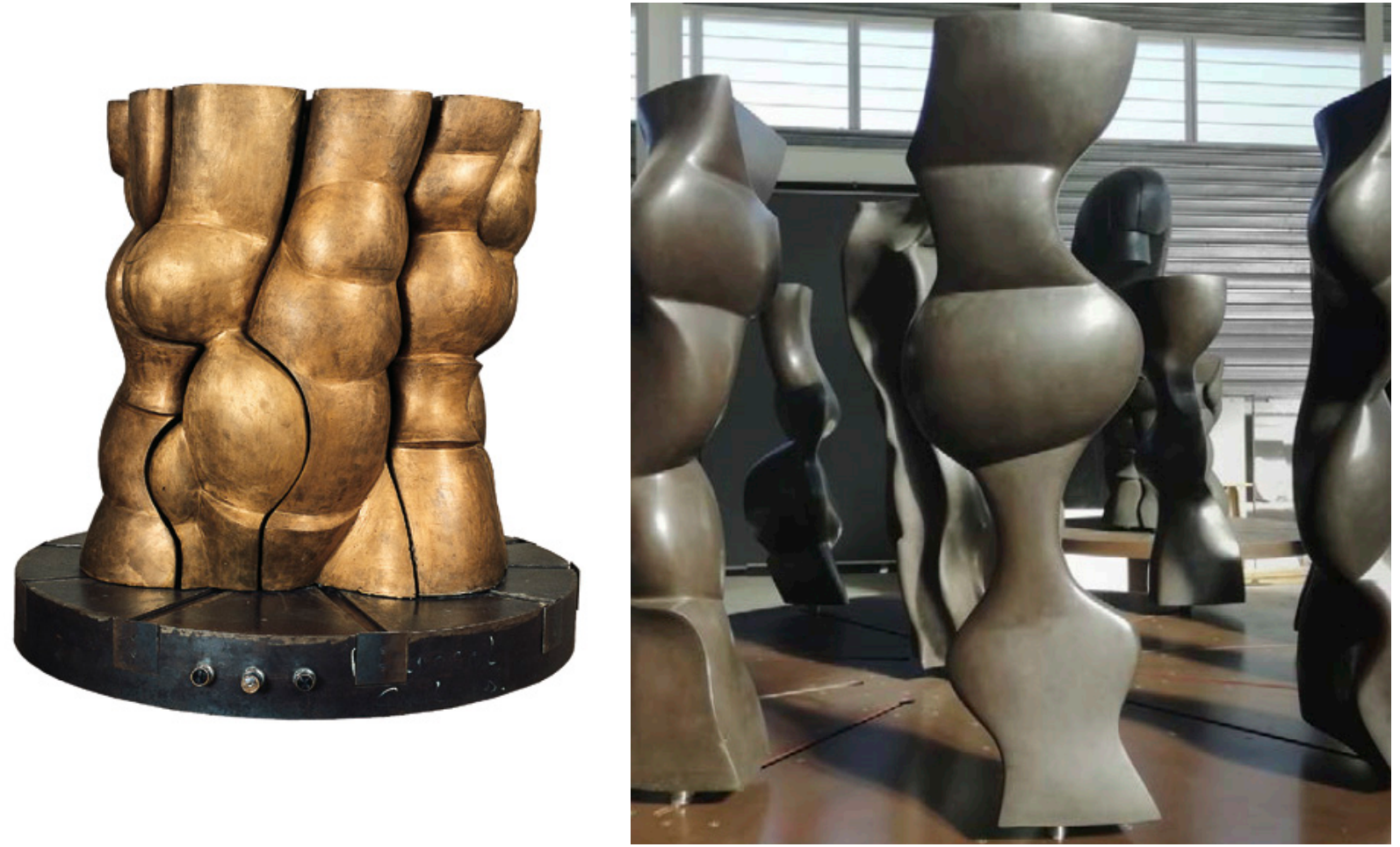

Fig. 21. Torso Cerruti, opus $172,1979$.

[Imagen proporcionada por la Fundación Escultor Berrocal, 2015].

A poco que se estudie la obra de Berrocal, puede advertirse rápidamente la intensa relación que tiene con las matemáticas -que Gardner trata profusamente ${ }^{8}$-, la geometría y por ende con la ingeniería, entre otras cosas, todas sus obras están concebidas como un rompecabezas cardo, siguiendo la definición de Anthony S. Filipiak, en su obra, 100 puzzles: How to make and solve them (1942). También existe otra importante aportación ensayística de Mercedes Siles Molina en referencia a las matemáticas de Berrocal titulada, la cual nos cuenta como a través de la obra de Berrocal se hacen palpables la magia y la belleza de las matemáticas (Molina, 2017).

Como hemos visto, no queda aquí la búsqueda del escultor, en su afán por la investigación llega a crear figuras articuladas y motorizadas. Y es que su discurso va más allá, y utiliza estas maestrías como una solución técnica para mostrar el interior y exterior de formas antropomorfas complejas y fragmentadas, y la mayoría de veces desnaturalizadas, profundizando en la esencia del hombre, tal como así se muestran en la mayoría de sus representaciones y donde a continuación mostramos algunos ejemplos.

Algunos artistas considerados entre la estética transhumanista se encuentran Orlan, Neil Harbisson, Stelarc (fig.22), Eduardo Kac (fig.23), Patricia Piccinini (fig. 24), entre otros.

\footnotetext{
${ }^{8}$ Así se describe en el documento facilitado por la Fundación Berrocal. Pero también en la revista Temas 77 de "Investigación y ciencia" con el subtítulo "Arte y matemáticas", donde compara las esculturas del malagueño Miguel Berrocal con rompecabezas mecánicos. El propio Gardner hizo referencia a las matemáticas y el arte de Berrocal en uno de sus libros: Mosaicos de Penrose y escotillas cifradas. (Penrose Tiles to Trapdoor Ciphers, 1989). Fue publicado en España por la editorial Labor en 1990, con el subtítulo "De los cardos a Berrocal"..
}

Umática. 2019; 2: 53-74 

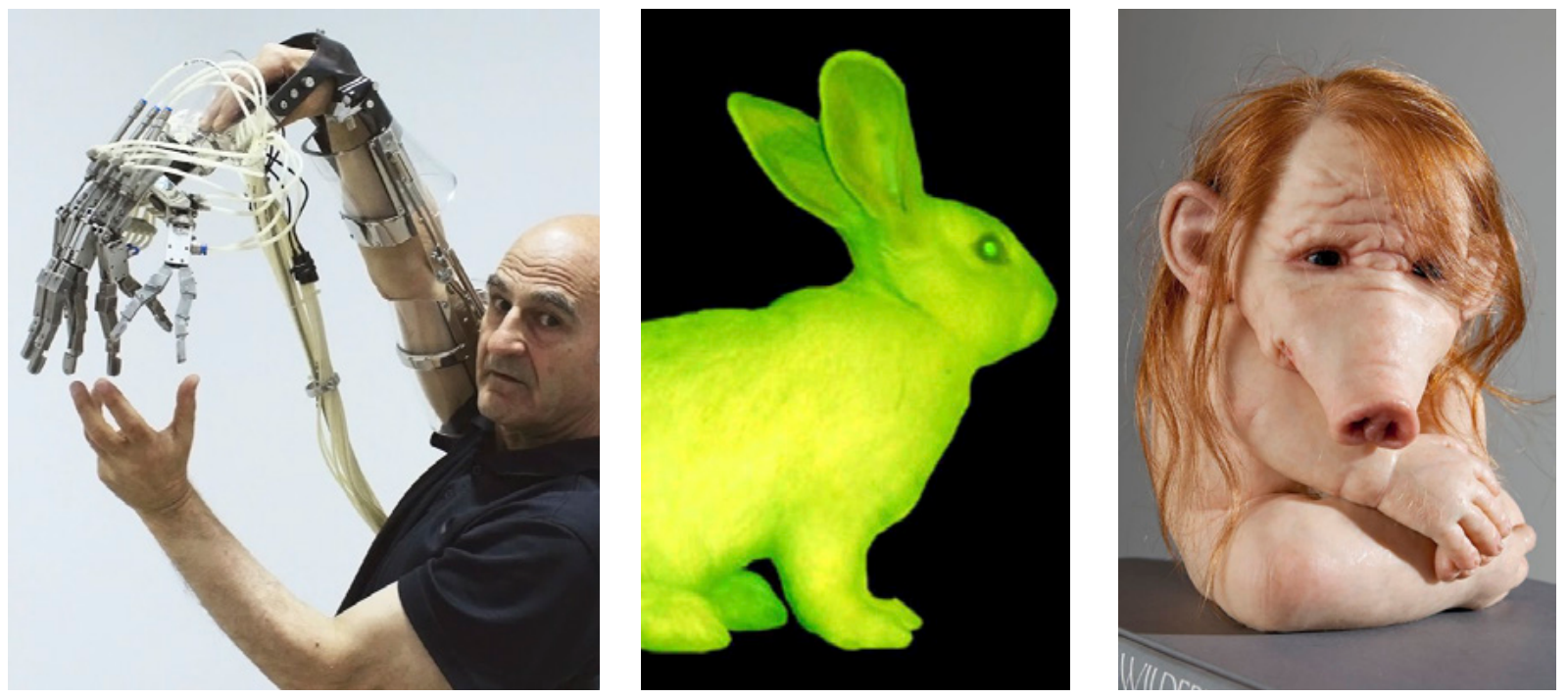

Habiendo esbozado el transhumanismo y algunos ejemplos de toque con el arte, un artista como Berrocal debió estar al tanto del desarrollo técnico de su tiempo por los títulos que alberga su biblioteca personal. Y aunque hubiese podido ser consciente o no de ello, existe un peso innegable del conocimiento, en mayor grado en el caso de Berrocal cuya obra requiere una técnica muy próxima a la ingeniería y de un gran poso científico, como apunta varias veces Rosario Camacho (2015) en su análisis.

No queremos decir con esto, que Berrocal conociese las teorías transhumanistas, o que reflexionase sobre la evolución del ser humano a través de sus obras. Pero si podemos pensar, que siendo un hombre de su tiempo e innovador -incluso adelantado-, llevase su forma expresiva por una preocupación en la figuración antropocéntrica y su resolución en identidades fragmentadas y reconstruidas. Aproximaciones en esa línea encontramos algunos ejemplos como los referenciados por Kosme Barañano (2002), Julían Gallego y Pedro Feduchi. Dando como resultado estético unos seres nuevos y en muchos casos resplandecientes. Siguiendo con Berrocal, cabe decir que sus obras tienen una fuerte componente hierática,-como las tendría un dios o un robot- que su anatomía es inventada (fig. 25), no realista, que en algunos casos hace réplicas de forma seriada (fig. 26), y en muchas ocasiones son figuras articuladas mediante mecanismos (fig. 28), o también podemos encontrar dentro de su estética las formas licuadas como esta (fig. 27) -la identidad líquida, que como describe Bauman (2006) tiene que ver con la forma de vida de las sociedades contemporáneas, caracterizada, cuyos individuos inmersos en una sociedad líquida, cambian las condiciones de actuación antes de fijar unos hábitos. Esta es otra característica de la sociedad digital actual y transhumanista-. Por todo ello queremos advertir que estas son características muy propias de un hombre nuevo, un hombre reinventado, ciborg y que aparenta estar más hecho de metal que de carne.

Fig. 22.

Third hand,

Stelarc, 1980.

[Adaptado de

Clotmag, por D.

Winter, 2016

Fig. 23.

Alba, conejo

fluorescente

alterado

genéticamente.

Eduardo Kac, 2000 .

[Imagen facilitada por @Eduardo Kac

Fig. 24.

The Student, escultura con pelo humano real de Patricia Piccinini, 2012.

[Imagen facilitada por (c) Patricia Piccinini]. 

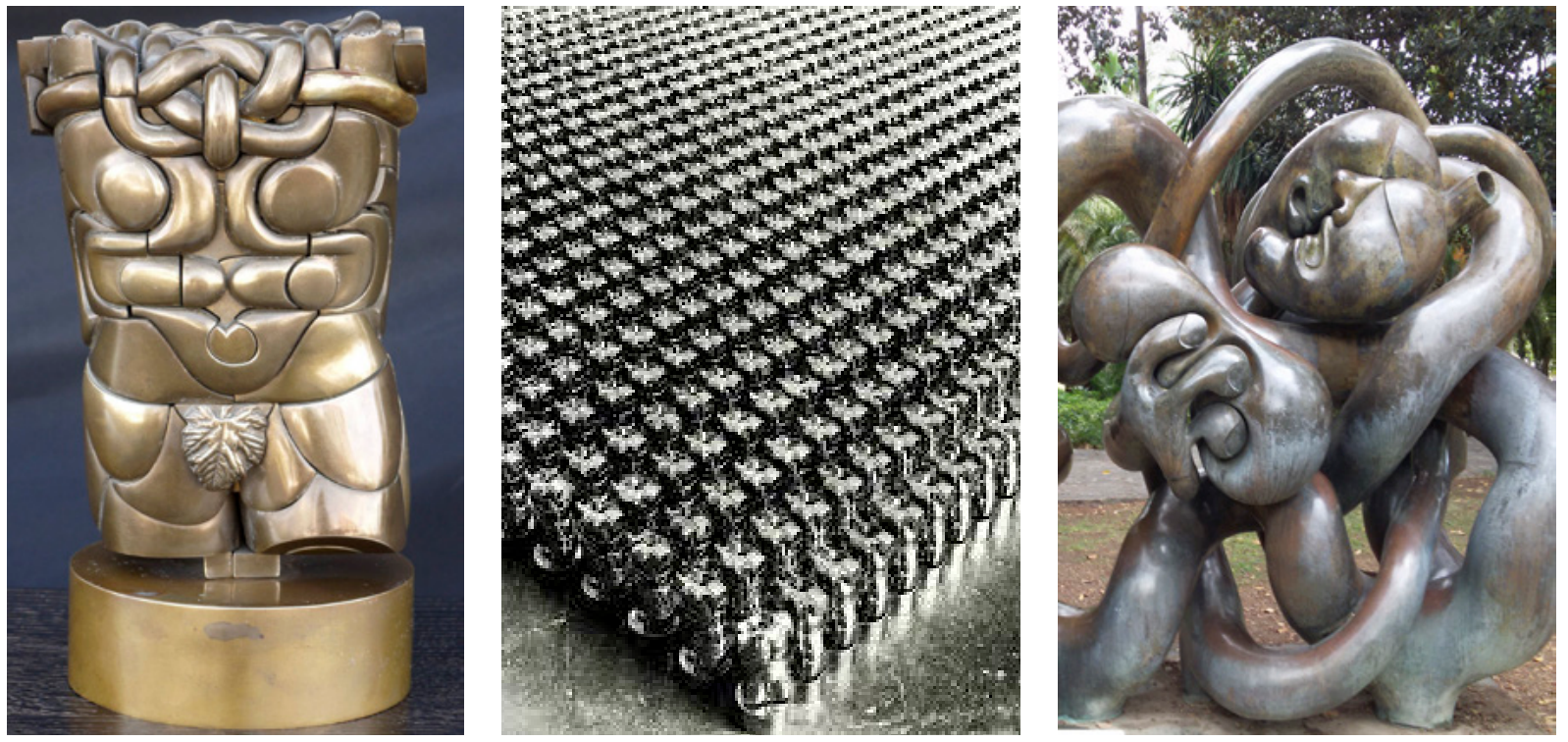

Fig. 25 .

4. Conclusión.

Goliath, opus 114.

Miguel Berrocal, 1968. Estatua de 80 piezas

Las ideas transhumanistas son relativamente recientes y han aportado numerosas narrativas a la literatura de ciencia ficción y al cine, pero respecto al arte plástico, sucede que la relación con estas ideas se hace a posteriori, es decir que existen ciertas formas de arte ins-

Fig. 26. tauradas con anterioridad al término sobre las que se pueden apreciar similitudes con algu-

Mini David, opus 107. Miguel Berrocal. Fabricados en serie, primera serie de 1969

Fig. 27.

Detalle de Siéxtasis. Estatua en homenaje a Pablo Picasso, 1977 nas de sus facetas - filosóficas o estéticas - y por tanto son susceptibles de tildarse como transhumanistas. Esto nos deja con, al menos, dos reflexiones que podrían ser ampliadas en futuros artículos. La primera, es la potencia del arte como elemento social para traspasar los límites de lo conocido, o más bien, para poner a prueba aquello que en un momento de la historia se considera un límite - y que por tanto no se puede franquear-e imaginar lo que queda fuera, lo inclasificado y hasta entonces inexplorado. La segunda es una pregunta: ¿Por qué hoy, que la tecnología y la ciencia acercan las ideas transhumanistas a nuestro presente más inmediata no hay mayor interés por el arte y la estética transhumana? Puesto que cuánto más avanza nuestro desarrollo tecnológico más cerca de nuestra cotidianidad está, la falta de preocupación, fascinación y reflexión alrededor de ello es, cuanto menos, curiosa.

Por otro lado, con la exposición que hemos realizado en este breve artículo, afirmar que la obra de Berrocal tiene una lectura transhumanista legítima es sostenible. No podemos decir, sin embargo, que esa lectura fuese o no conocida o compartida por el propio Berrocal. A la luz de los escritos que de él tenemos, de sus entrevistas y sus conversaciones con otros artistas, solo podemos asegurar que tenía una fijación con la corporeidad humana y el concepto de la "multiplicidad" (Ministerio de Cultura, 1984). La concepción en piezas dentro de piezas, siendo todas extrañas y complejas formas geométricas que parecen no ser parte de nada, pero que se unían para formar un todo distinto y mayor, reflejan ideas filosóficas mucho más antiguas, como la relación entre lo uno y lo múltiple o el todo mayor que la suma de las partes. Es razonable suponer que las ideas previas al transhumanismo -como pueden ser las 

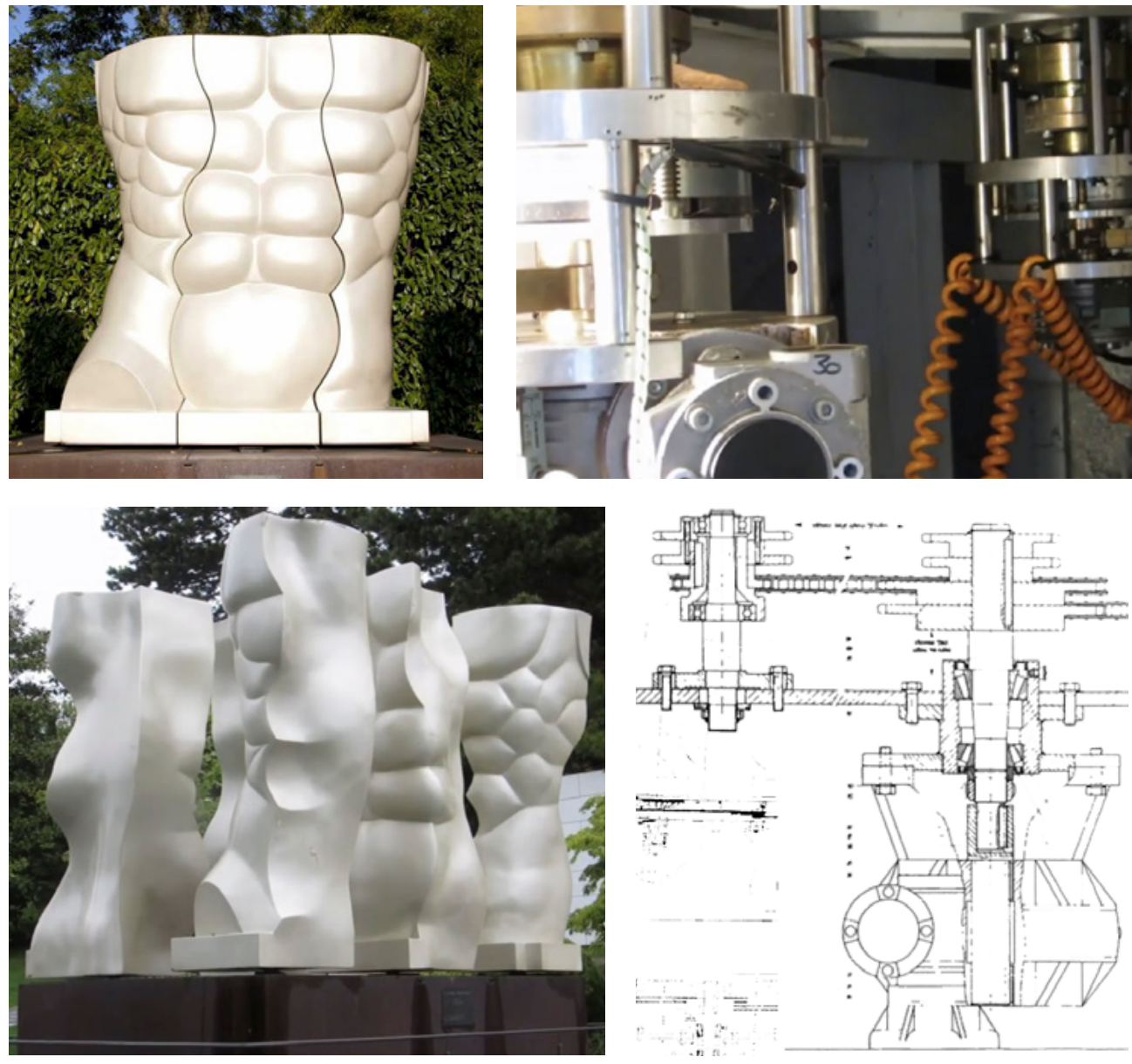

ideas sobre los ciborgs y los robots- eran de interés para Berrocal, según conversación con Cristina Blais9 :"coleccionaba robots y era un asiduo lector de Asimov y Aldous Huxley" hermano del mencionado Julian Huxley. Además por encargo del Ayuntamiento de Toledo asesoró y trabajó en la restauración de artilugios de Juanelo Turriano, erudito del s.XVI en España al que se le adjudican importantes inventos de ingeniería y un autómata hecho de madera llamado Hombre de palo ${ }^{10}$-existencia no demostrada-..

Para empezar, en las obras de Berrocal, especialmente en las de su última etapa, aparecen figuras compositivas que giran en torno a la segmentación. Es una dimensión transformadora, que se podría criticar por ser hasta cierto punto tímida. El torso de Citius Altius Fortius se descomponía para volver a componerse de nuevo. Un ejercicio de autodescubrimiento, pero no de metamorfosis. Sin embargo, es precisamente ese el primer paso: concebir la posibilidad de la segmentación más allá de lo conocido. Trabaja también, cómo es habitual en la estética transhumanista, con representaciones parciales, elementos fraccionados o separados, brazos, piernas, cabezas y torsos sin continuidad de un cuerpo completo. Con

\footnotetext{
9 Cristina Blais de Sajonia-Coburgo Gotha y Braganza, viuda de Miguel Ortiz berrocal

$10 \quad$ Fundación Juanelo Turriano. (https://www.juaneloturriano.com/)
}

Umática. 2019; 2: 53-74
Fig. 28.

Citius Altius

Fortius. Instalada en Lausanne, Musée Olympique, Suiza. 1993.

Fig. 29.

Detalle de los motores interiores de Citius Altius Fortius, 1993.

Fig. 30. Citius Altius Fortius. Imagen de la obra desestructurada, 1993.

Fig. 31.

Planos de Citius Altius Fortius, 1993. Esta pieza destaca por moverse con un complejo sistema electromecánico que permite que la obra se divida en piezas, para pasado un tiempo volver a reintegrase como unidad. (Imágenes facilitadas por la (C)Fundación Escultor Berrocal, 2008). 
frecuencia, sus representaciones están deformadas o contienen elementos que no existen, cómo músculos inventados, inflamados o redondeados hasta ser esferas, o juegos directos de pareidolia, como en los Almogávares o en Romeo e Julieta. Esto está relacionado con su fijación por las formas antropomórficas y la expansión de sus límites para la mente del observador. ¿Cuándo lo humano nos deja de parecer humano? Sumemos también el interés por la replica y la seriación, especialmente con la producción industrial en metal, la dimensión de corte entre la ingeniería y el arte. Aunque no todas sus obras se produjeron en serie, su modo de creación las hacía, de hecho, seriables. Y por supuesto, las formas de representación están fuertemente ligadas a la relación entre el hombre y la máquina, tanto en su relación como herramienta creativa cómo en la unión de ambos elementos en uno en sus obras motorizadas.

Por otro lado, si bien ya hemos aclarado que el transhumanismo no estaba explicitamente en las ideas de Berrocal, si que estaba presente en el modo de elegir sus métodos, técnicas y discursos particulares, que terminaron haciendo única su producción, una nueva confluencia, esta vez filosófica. De entre todos estos principios transhumanistas podemos destacar: su interés por la ciencia y la tecnología son clave para dirigir su obra, su manera de abordar la humanidad es también una actualización del antropocentrismo, la técnica y la tecnología son herramientas cristalizadoras de la obra de arte y de la dimensión estética, la búsqueda actualizada de lo radicalmente humano — la clásica esencia — es su inquietud primera o cómo el fraccionamiento lleva a la recomposición del cuerpo describiendo un ciclo de enriquecimiento.

Por lo tanto, podemos concluir que sí es posible una reinterpretación actual de la obra de Berrocal, del mismo modo que sí es posible clasificarlo, al menos, como arte con una dimensión transhumanista. Todavía cabría discutir si su obra tiene el peso suficiente como para servir de inspiración para la estética posthumanista y más allá, cuánto puede ofrecer al planteamiento del arte más tecnológico hoy: ¿Cuánto podríamos relacionar con la estética emergente en torno al individuo, el entorno, la identidad y la problemática hibridación humano-máquina que vivimos actualmente en la realidad aumentada que dibuja nuestro uso del internet de las cosas y las redes sociales? Los planteamientos tecnológicos más cotidianos sitúan el horizonte de nuestro futuro próximo más cerca de una revolución mental por la ruptura de los límites de nuestra privacidad y nuestra individualidad que afecta directamente al modo de entendernos a nosotros mismos y nuestra relación con el mundo por encima de la transformación corpórea directa. Sin embargo, la alteración en nuestra percepción de la realidad altera, a su vez, nuestra percepción de nuestra corporeidad y de nuestros límites físicos. Para muchos de nosotros nuestro teléfono inteligente funciona como extensión de nuestro cuerpo y se integra en nuestra actividad social normalizada, tanto que perderlo implica una pérdida de capacidades que nos deja temporalmente "amputados". La actual crisis mundial por el COVID no está sino acelerando esta situación. Marko Kolanovic, jefe global de investigación macrocuantitativa y de derivados en J. P. Morgan, avisaba que personas que no pueden costearse un ordenador y conexión a internet ven tan mermadas sus posibilidades de interacción con el mundo que, de no recibir el apoyo adecuado, caerán más bajo aún en los 
segmentos económicos, llegando fácilmente a ser incapaces de abandonar los umbrales de la pobreza (Ponce de León, 12 de septiembre de 2020).

Aún está por ver cómo se reflejará este cambio en el arte y la estética de este siglo, pero está claro que la inquietud por los límites del cuerpo humano y sus posibilidades de cambio no está agotada. Seguramente, la obra de Miguel Berrocal todavía pueda darnos algunas claves para explorar nuestros límites.

\section{Referencias Bibliográficas / References}

AMADOR BECH, J. (2017). El significado de la obra de arte. Conceptos básicos para la interpretación de las artes visuales. México D.F, México: Universidad Nacional Autónoma de México.

BAUMAN, Z (2006), Vida Líquida. Paidós (ed.), Barcelona: p. 9.

BOSTROM, N. (2011). «A history of transhumanist thought». Originalmente publicado en 2005 para el Journal of Evolution and Technology 14 (1). Revisado para su reimpresión en Carl, L., y Rectenwald, M. (Ed.). (2011). Academic Writing Across the Disciplines, New York: Pearson Longman. Recuperado de https://www.nickbostrom.com

CAMACHO MARTINEZ, R. (2015). «Berrocal. El arte de innovar». Anuario 2015 Real Academia De Bellas Artes De San Telmo De Málaga, (15), pp. 78-9o. Recuperado de https://www.realacademiasantelmo.org/berrocal-el-arte-de-innovar/

CARDOZO, J.J., y CABRERA, T. M. (2014). «Transhumanismo: concepciones, alcances y tendencias». Análisis. Revista Colombiana de Humanidades, 46 (84), pp. 63-88. Recuperado de https://www.redalyc.org/toc.oa?id=5155\&tnumero=51535

CLYNES, M. E.,y KLINE, N. S. (1960). «Cyborg and space». Astronautics, 5(9) pp. 26-27, 74-76. Recuperado de https://moviesz.nytimes.com/library/cyber/surf/022697surf-cyborg.html

CHARLES, N. y CARTER, B. (2013). «Animals, agency and resistance». Journal for the Theory of Social Behaviour, 43 (3), pp. 322-340. doi: 10.1111/jtsb.12019

DARD, O. y MOATTI, A. (2016). «Aux origines du mot "transhumanisme"». Futuribles, 413, pp. 85-94.

FEDUCHI, P. (2000) Fundación Unicaja, Dialécticas, Italcable (ed.), Málaga: pp. 36-43.

FILIPIAK, A. S., (1942). 100 puzzles: How to make and solve them. Illinois: Barnes and Co.

FUNDACIÓN UNICAJA. (2000). Catálogo de la exposición Berrocal. Sala Unicaja

"Italcable". Málaga: Fundación Escultor Berrocal para las Artes.

GÁLLEGo, J., PASSONI, F., BERROCAL, M. El taller de Berrocal. Ministerio de Cultura,

Dirección General de Bellas Artes y Archivos.(ed.) Madrid: El Viso, 1984, p. 11.

GARDNER, M. (1978). «Mathematical Games». Scientific American, 238(1), pp. 14-27. Recuperado de https://www.scientificamerican.com/article/mathematical-games-1978-01/

GARDNER, M. (1990). Mosaicos de Penrose y escotillas cifradas. Barcelona: Editorial Labor.

HAMBURSKI, B. (1985), Approche pour une comprensión. Catálogo de

la exposición de Berrocal. Bruselas: Le Botanique, 
HARAWAY, D. J. (1991). Ciencia, cyborgs y mujeres. La reinvención de la naturaleza, Madrid: Ed. Cátedra.

HARRISON, P., y WOLYNIAK, J. (2015). «The History of "Transhumanism"». Notes and Queries, 62 (3), pp. 465-467.

HAYLES, K. (1999). How We Became Posthuman: Virtual Bodies in Cybernetics,

Literature and Informatics. Chicago, IL, EE UU: University of Chicago Press.

HUXLEY, J. (1957). New Bottles for new wine: Essays. Londres. U.K.: Ed. Chatto and Windus.

HUXLEY, J. (1986). Leaves of the tulip tree. London: Murray.

IVAM, I. (2002). Catálogo de exposición. Berrocal, M. Valencia: Barañano,

K. (coord.). Institut Valencià d'Art Modern, p. 9

KURZWEIL, R. (2012). La Singularidad está cerca: Cuando los humanos

transcendamos la biología. Berlín: Lola Books.

LE BOTANIQUE. (1985). Catálogo de la exposición Rétrospective Berrocal 1955-1985.

Bruselas: Centre Culturel de la Communauté Française Walloni-Bruxelles.

MEDINA, M. (2003). «La cultura de la tecnociencia». En Bueno, C. y Santos, Mạ. J.

(Coords.), Nuevas tecnologías y cultura (pp. 29-74). Madrid: Akal.

MinISTERIO DE CULTURA. (1984). Catálogo de exposición Antológica Berrocal

(1955-1984). Madrid: Dirección General de Bellas Artes.

MORGAN, ROBERT C. (1999). «Berrocal. The puzzle of existence». Sculpture, 18 (3). Recuperado de https://www.sculpture.org/documents/scmaggg/aprilgg/berro/berro.html

MOYA, C. (2006). Filosofía de la mente. Valencia: Universitat de Valencia.

PARSONS, H. M., y KeARSLEY, G. P. (1982). «Robotics and Human Factors: Current Status and Future Prospects». Human Factors, 24 (5), pp. 501-508. [doi: 10.1177/001872088202400504]

PONCE DE LEÓN, R. (12 de septiembre de 2020). Habrá ganadores y perdedores en la crisis de la COVID: se impone un modelo de recuperación en $\mathrm{K}$ que agrandará las desigualdades. El diario. es. Recuperado de https://www.eldiario.es/economia/habra-ganadores-perdedores-crisiscovid-impone-modelo-recuperacion-k-agrandara-desigualdades_1_6216002.html

SILES MoLINA, M. (2017). «Cultura y matemáticas: El alma matemática de Miguel Berrocal». Boletín de la Titulación de Matemáticas de la UAL, 10(3), 10-11. Recuperado de https://cutt.ly/RfOkwWT

StePhens E., y Heffernan T. (2016). «We Have Always Been Robots: The History of Robots and Art». En Herath D., Kroos C., y Stelarc (Eds.), Robots and Art. Exploring an Unlikely Symbiosis (pp. 29-45). Singapore: Springer.

TORRIJOS PAREJA, F. (2004). «Estéticas transhumanas: del cyborg al androide». Scripta Nova, 8 (170/53). Recuperado de http://www.ub.edu/geocrit/sn/sn-170-53.html

VITA-MORE, N. (2010). «Aesthetics of the radically enhanced human».

Technoetic Arts, 8 (2) pp. 207-214. doi: 10.1386/tear.8.2.207_1 